\title{
Duygusal Tükenmişliğin, Duygusal Bağlılık Üzerine Etkisi (The Effect of Emotional Burnout on Emotional Commitment)
}

\section{Ali CANER iD a Belgin AYDINTAN iD}

a Ankara Hacı Bayram Veli Üniversitesi, Lisansüstü Eğitim Enstitüsü, İşletme A.B.D., Ankara, Türkiye, ali66caner06@gmail.com

b Ankara Hacı Bayram Veli Üniversitesi, İktisadi ve İdari Bilimler Fakültesi, Ankara, Türkiye, belgin.aydintan@hbv.edu.tr

\begin{tabular}{|c|c|}
\hline MAKALE BİLGİSİ & ÖZET \\
\hline $\begin{array}{l}\text { Anahtar Kelimeler: } \\
\text { Tükenmislik }\end{array}$ & $\begin{array}{l}\text { Amaç - Araştırmanın temel amacı, Ankara'da çalışan serbest mali müşavirlerin duygusal } \\
\text { tükenmişlik ile duygusal bağlılık seviyelerini ölçerek mevcut durumu ortaya koymaktır. }\end{array}$ \\
\hline $\begin{array}{l}\text { Örgütsel bağlllık } \\
\text { Mali müşavir }\end{array}$ & $\begin{array}{l}\text { Yöntem - Yapılan anket çalışmasında Maslach'ın tükenmişlik ölçeği ile Allen ve Meyer'in } \\
\text { örgütsel bağlllık ölçeği kullanılmıştır. Çalışmada duygusal tükenmişlik ile duygusal bağllık } \\
\text { karşıllaştırılmıştır. Anketler Ankara'da çalışan serbest mali müşavirlere dağıtılmıştır. Elde edilen } \\
247 \text { anketle analiz yapılmış ve bulgular SPSS } 23 \text { programı ile değerlendirilmiştir. Duygusal } \\
\text { tükenmişliğin duygusal bağlllığa etkisi, korelasyon analizi ve regresyon analiziyle tespit } \\
\text { edilmiştir. }\end{array}$ \\
\hline Kabul Tarihi 20 Ağustos & $\begin{array}{l}\text { Bulgular - Bulgular çalışmanın başında belirtilen kavramsal çerçeveyi büyük oranda } \\
\text { desteklemektedir. Buna göre, duygusal tükenmişlik, duygusal bağlllığı negatif ve anlamlı olarak } \\
\text { etkilemektedir. Bu iki boyut arasında negatif bir ilişki bulunmuştur. Buna göre duygusal } \\
\text { tükenmişlik arttıkça, duygusal bağlllığın azaldığı tespit edilmiştir. }\end{array}$ \\
\hline Araştırma Makalesi & $\begin{array}{l}\text { Tartışma - Tükenmişlik azaltıldığı ya da bitirildiği zaman örgütsel bağlılı̆̆ı azaltan olumsuz bir } \\
\text { sebep de azalmış ya da bitmiş olacaktır. Böylece işgörenlerin örgüte bağlanma oranları da artmı̧ } \\
\text { olacaktır. Bunun için bireylere, örgütlere ve devletlere tükenmişlikle mücadelede görev ve } \\
\text { sorumluluklar düşmektedir. }\end{array}$ \\
\hline
\end{tabular}

\begin{tabular}{|c|c|}
\hline ARTICLE INFO & ABSTRACT \\
\hline $\begin{array}{l}\text { Key Words: } \\
\text { Burnout } \\
\text { Organisational commitment } \\
\text { Financial advisor } \\
\text { Received } 29 \text { May } 2019 \\
\text { Revised } 25 \text { July } 2019 \\
\text { Accepted } 20 \text { August }\end{array}$ & $\begin{array}{l}\text { Purpose - The main purpose of the study is to determine the current situation by measuring the } \\
\text { levels of emotional burnout and emotional commitment of independent financial advisors } \\
\text { working in Ankara. } \\
\text { Design/methodology/approach - In the survey, Maslach's burnout scale and Allen and Meyer's } \\
\text { organizational commitment scale were used. In the study, the sub-dimension of burnout, } \\
\text { emotionality and sub-dimension of organizational commitment, were compared. The analysis was } \\
\text { started with } 247 \text { questionnaires which were distributed to free financial advisers working in } \\
\text { Ankara and the findings were evaluated with SPSS } 23 \text { program. The effect of burnout on } \\
\text { organizational commitment was determined by correlation analysis and regression analysis. } \\
\text { Findings - The findings strongly support the conceptual framework mentioned at the beginning } \\
\text { of the study. Accordingly, emotional burnout affects emotional commitment negatively and } \\
\text { significantly. A negative relationship was found between these two dimensions. Accordingly, it } \\
\text { was found that emotional burnout decreased as emotional burnout increased. } \\
\text { Discussion - When burnout is reduced or terminated, a negative cause that reduces } \\
\text { organizational commitment will also be reduced or exhausted. Thus, employees' attachment to the } \\
\text { organization will be increased. Therefore, individuals, organizations and states have duties and } \\
\text { responsibilities in the fight against burnout. }\end{array}$ \\
\hline
\end{tabular}

\section{GİRiş}

Küreselleşen dünya ile birlikte örgütler arası rekabet artmış ve örgüt içindeki insan unsuru daha da önem kazanmıştır. Bu nedenle başarılı olmak isteyen örgütler kendi mevcut çalışanlarını muhafaza edecek ve personel devir hızını düşürerek hem maliyet açısından hem de nitelik açısından fayda elde etmek isteyeceklerdir. Bu nedenle örgütsel bağll1lk bütün örgütler açısından son derece önem arz etmektedir. Örgütsel bağlılığın önemli olduğunun bilinmesi tek başına yeterli olmamakta, aynı zamanda bu bağlılığı etkileyecek durumlarında bilinmesi ve buna göre önlem ve çareler aranması gerekmektedir. Bu bağlamda 


\section{A. Caner - B. Aydintan 11/3 (2019) 1656-1662}

işgörenlerin, örgütsel bağlılığının sağlanması için yaptıkları işleri sevmeleri ve maddi ve manevi olarak menfaat beklentilerinin tatmin edilmesi gerekmektedir..

İşgörenlerin çalıştıkları ortamda çeşitli sıkıntı ve problemlerle karşı karşıya kalması onların örgütsel bağlılığını olumsuz yönde etkilemektedir. Bu olumsuz özelliklerden birisi de tükenmişliktir. Tükenmişlik iş görenlerin kendilerine, aile ve iş ortamındaki kişilere karşı besledikleri olumsuz duygu ve düşünceler sarmalıdır. Dolayısıyla tükenmişlikten sadece bireyler değil aynı zamanda örgütler ve ailelerde olumsuz olarak etkilenmektedir. Çünkü örgütten ayrılan işgörenin yerine yeni bir işgörenin alınması, seçilmesi ve eğitimi, örgütlere maddi bir külfet olmaktadır. Bu nedenle bu çalışmanın amacı da tükenmişlik ve örgütsel bağlllık arasındaki ilişkiyi mali müşavirler üzerinde incelemektir. Bu bağlamda Ankara' da bulunan serbest mali müşavirlerin duygusal tükenmişlik ile duygusal bağlllıkları incelenmiştir.

Çalışmada Maslach'ın tükenmişlik ölçeği kullanılmıştır. Bu ölçekte üç alt boyut vardır. Bunlar; duygusal boyutu, duyarsızlaşma boyutu, kişisel başarı boyutudur. Örgütsel bağlılık için ise Allen ve Meyer'in ölçeği kullanılmıştır. Allen ve Meyer'in örgütsel bağllık ölçeği ise duygusal bağlılık, zorunlu bağlılık ve normatif bağlılık olmak üzere 3 boyuttan oluşmaktadır. Bu makalede ise sadece tükenmişliğin duygusal boyutu ile örgütsel bağllı̆ı̆ın duygusal boyutu incelenecektir.

\section{KAVRAMSAL ÇERÇEVE}

\subsection{Tükenmişlik}

İngilizcede "Burnout" sözcügüne dayanan tükenmişlik, Türkçede "gücünü yitirmiş olma, çaba göstermeme durumu" anlamına gelmektedir(TDK, 2019).

Tükenmişlik günümüzde Maslach'la birlikte anılmaktadır. Maslach'a göre tükenmişlik;fazla duygusal talebe maruz kalan, aynı zamanda devamlı olarak diğer işgörenlerle yüz yüze çalışmak durumunda olan bireylerde daha çok görülmektedir. Tükenmişlikle birlikte işgörende yorgunluk, bitkinlik, çaresizlik ve umutsuzluk görülmektedir. Daha sonra bu tükenmişlik durumunda işgören, yapılan işe, hayata ve diğer bireylere karşı olumsuz tutumlar sergilemeye başlar(Maslach ve Jackson,1981:99).

Tükenmişlikle günümüzde çok fazla karşılaşılması ve öneminin her geçen gün daha fazla anlaşılması nedeniyle hakkında çok fazla araştırma yapılmıştır. En basit ifadesiyle ruhsal ve fiziksel açıdan enerjinin tükenişi şeklinde ifade edilen ve çalışma ortamıyla bireyin etkileşiminin bir sonucu olduğu bakış açısıyla hem bireyler hem de örgütler açısından dikkate alınması gereken konuların başında gelmektedir (Budak ve Sürgevil, 2005: 95).

\subsubsection{Maslach Modeli}

Günümüzde tükenmişlik konusunda en çok benimsenen tanım Christina Maslach ve arkadaşları tarafından oluşturulan tükenmişlik modelinde bulunmaktadır. Maslach ve arkadaşları tarafından oluşturulmuş tükenmişlik modeli 3 alt boyuttan meydana gelmektedir. Bu boyutlar; duygusal tükenme(emotional exhaustion), duyarsızlaşma(depersonalization) ve kişisel başarı(personel accomplishment)dır(Maslach ve Jackson,1981).

Tükenmişliğin sürecini açıklamaya çalışan yukarda sayılan bu üç boyut arasındaki farklılık her zaman gözetilmelidir. Yapılan çalışmalarda bu boyutların hem nedenleri hem sonuçları birbirinden farklıdır.

Duygusal tükenme boyutu: Duygusal tükenme boyutunda olan kişi, yapmış olduğu işlerde verimsiz olduğunu ve talepleri karşılamadığını düşünmektedir. İşe gittiği her gün bu durum tekrar etmektedir. İş gören bu yüzden tekrar tekrar stres ve gerginlik yaşamaktadır.Bu durumda kişide farklı sağlık sorunları ortaya çıkmaktadır(Leiter ve Maslach, 1988; Friesen ve Sarros, 1989; 1995; Torun, 1997; Çimen ve Ergin, 2001).

Duyarsızlaşma boyutu: Tükenmişliğin bu boyutu kişiler arası ilişkiyi ifade etmektedir(Budak ve Sürgevil, 2005: 96). İşgörenin iş yerindeki çalışanlara ve müşterilere karşı duygusuz bir tutum takınması bu boyutun en büyük göstergesidir. Yani duyarsızlaşma; işgörenin muhatap olduğu kişileri umursamadan, onları görmüyormuş ve duymuyormuş gibi iş yapmaya çalışması olarak adlandırılabilir. Böylece arada kapanmaz uçurumlar oluşur ve işgören geri dönüşü zor olan bir yola girmiş olur(Çalgan ve Yeğenoğlu, 2009:63). 


\section{A. Caner - B. Aydintan 11/3 (2019) 1656-1662}

Kişisel başarı boyutu: Maslach'ın tükenmişlik sendromu için geliştirdiği bu modelde son aşama olan kişisel başarı boyutunda ise kişi kendisine karşı ağır eleştiriler yaparak kendisini başarısız olarak görmektedir. Tükenmişliğin bu aşamasında bulunan işgörenler, hem kendi bilgilerini hem yeteneklerini gereksiz ve yetersiz görmektedirler. İşgörenler herhangi bir sıkıntı durumunda bu problemi kendisi oluşturmuş zanneder ve kendilerini işten uzaklaştırmaya başlarlar. Bu negatif değerlendirmelerde bulunan bireyler, yapmış olduğu bir işin başarısızlık ile sonuçlanması durumunda probleme kendisinin neden olduğunu düşünür ve işten uzaklaşmaya başlar (Özgüner, 2011: 56).

\section{2.Örgütsel Bağlılık}

Örgüt kelimesi, Yunanca “Organon" ve Latince “Organum” kelimelerinden geliştirilerek günümüz Türkçesindeki yerini almıştır(Ülgen,1997). Örgüt belirli hedef veya hedefler noktasında aynı tutum ve görüş birliğinde olan insanlar topluluğuna verilen isimdir. Aynı zamanda bir oluşumun örgüt olabilmesi için tek bir birey ya da tek bir gruba bağlı olarak oluşması da önemlidir. Bireyler bazen tek başlarına bazen de grup halinde yaşama, hedeflerini gerçekleştirme isteğinde ve kararlılığında olabilirler. Bu nedenle tek başlarına yapamadıkları veya birlikte daha iyi sonuç alacakları işler için bir örgüt etrafında toplanmayı tercih edebilirler(Tosun,1997). 1956 yılında White tarafından literatüre dahil edilen örgütsel bağlllık daha sonra başta Porter olmak üzere Mowday, Allen, Meyer, Becker gibi çok fazla kişi tarafından geliştirilerek son halini almıştır. 1956 yılından beri devam eden bu süreç birbirinden faklı ve çeşitlilikte tanım ve içeriğe sahiptir(Paula C. Morrow, James C. McElroy,1988, akt:Tuğçe Üresin).Bu makalede ise Allen ve Meyer'in modeli kullanılmıştır.

\subsubsection{Allen ve Meyer'in Örgütsel Bağlılık Modeli}

Örgütsel bağlılık çalışmalarında genellikle Allen ve Meyer modeli kullanılmaktadır. Bu çalışmada da Allen ve Meyer'in modeli kullanılmıştır. Model örgütsel bağlılığı duygusal bağlılık, zorunlu bağl1lık ve normatif bağllık olmak üzere 3'e ayırmaktadır.

Duygusal Bağlılık: Bu boyut iş görenin örgütle bütünleşmesini göstermektedir. Bu nedenle örgütler için son derece önemli bir boyuttur. İşgören örgütsel amaç ve değerlere önem vermelidir. Aynı zamanda inançlarını eyleme çevirerek örgüt yararına çaba sarf etmesi de son derece ehemmiyetlidir. Bu bağlılık davranışlar ve tutumlar arasındaki uyum neticesinde olmaktadır(Siegel ve Siyase, 1997 akt:Soykan, 2012).

İnce ve Gül(2005)'e göre bu boyut, kişinin kendisini örgütün bir parçası olarak görmesinden dolayı çok önemlidir. Duygusal bağlılığı fazla olan işgörenlerde örgütün performansı ön planda olmakta ve , işgören örgüt başarısını veyazararınıkendisininmişgibihissetmektedir.

Zorunlu(Devam) Bağlılık: Akılı bağlılık da denilen bu bağl1lık Allen ve Meyer tarafından oluşturulmuştur. Zorunlu bağllılı, örgütten çıkmanın bedelinin bilincinde olmak anlamına gelmektedir. Tabir-i diğerle zorunlu bağlılık örgütten ayrılmanın bedelinin fazla olacağının bilinmesi nedeniyle, örgüt üyeliğinin mecburiyet nedeniyle devam ettirilmesidir(Lamsa ve Savolainen, 2000,akt:Soykan,2012).

Normatif Bağlılık: Ahlaki bağlılık da diyebileceğimiz bu bağlılık da iş gören örgütüne bağlı kalmayı ahlaki bir vazife olarak görmektedir. Bu nedenle işgörende sorumluluk duygusu fazlaysa, o nispette normatif bağlılık da artacaktır. Örgütte kalmak belli bir değer yargısı ve düşüncesi gerektirdiği için örgütten ayrılan iş gören, vazifesini yerine getirmediği düşüncesiyle suçluluk hissedecektir (Meyer ve Allen, 1991; Emhan .ve Gök, 2011).

\section{LITERATÜR TARAMASI}

Cho'nun yapmış çalışmada, devam bağlılığıyla kişisel başarı hissi arasında; duygusal bağlılıkla, duyarsızlaşma arasında; normatif bağlılıkla, duygusal tükenme ve duyarsızlaşma arasında; negatif bir ilişki olduğu sonucuna varılmıştır(Çetin, Basım ve Aydoğan,2011;64/65). Farklı bir çalışmada Tan ve Akhtar(1998:320), normatif ve duygusal bağl1lığın, duygusal tükenme ile olan ilişkisini belirlemek için Çin kültürüne yönelik çalışma yapmışlardır. Duygusal bağlılık ve normatif bağlılık ile duygusal tükenme arasında benzer yönlü bir ilişkinin bulunmuştur.Ayrıca duygusal tükenmenin, normatif bağlllık tarafından etkilendiği sonucuna varmışlardır(Civanoğlu,2015).

Örgütsel bağlllık ve tükenmişliğin belirtileri ve sonuçları benzer olmakla birlikte örgütsel bağlılık ve tükenmişlik arasındaki ters ilişki olması dolayısıyla öncüller, bir boyutu negatif şekilde etkilerken diğer 


\section{A. Caner - B. Aydintan 11/3 (2019) 1656-1662}

boyutu pozitif olarak etkilemektedir. Sonuçlar ise örgütsel bağlılık tarafından pozitif yönde etkilenirken tükenmişlik tarafından negatif olarak etkilenmektedir(Güleryüz, 2008: 1632).

\section{YÖNTEM}

Araştırmada veri toplamak için anket yöntemi kullanılmıştır. Tükenmişlik ve örgütsel bağllık düzeylerini belirlemeye yönelik yazın taraması yapılmıştır. Araştırmada uygulanacak olan nihai anket oluşturulmadan önce 264 adet anket elde edilmiş ve daha sonra gerekli düzenlemeler yapılarak bu sayı 247 ankete indirilmiştir. Bu uygulama da Ankara'da görev yapan serbest mali müşavirlerle yüz yüze görüşülerek anket yöntemi uygulanmıştır. Anketin içeriğinde; 9 soruluk demografik soru, Allen ve Meyer'in çalışmasından esinlenilerek oluşturulan örgütsel bağllık düzeyini ölçecek 24 soru ve tükenmişlik seviyesini ölçecek 22 soruluk Maslach'ın ölçeği kullanılmıştır. Bu makalede ise sadece tükenmişliğin duygusal boyutunu ölçen 9 soru ve örgütsel bağlılığın duygusal boyutunu ölçen 8 soru baz alınarak analiz yapılmıştır. Bu çalışmada elde edilen veriler SPSS 23 paket programı yardımı ile değerlendirilmiştir. Verilere ilişkin frekans ve yüzde değerleri verilmiştir.

Anket Ankara'daki serbest mali müşavirlere yapılmıştır. Bu mali müşavirler kendi işini yapan değil, başkasının yanında çalışan mali müşavirlerdir. Çünkü bu çalışmada işgörenlerin çalıştkları örgüte bağlllkları araştırılmışıı. Kişisel bilgilerin gizliliği korunarak veriler elde edilmiştir. Tükenmişlik ve örgütsel bağlllığa ilişkin değerlendirmeler; "kesinlikle katılıyorum" seçeneğine 5, "kesinlikle katılmıyorum" seçeneğine 1 puan verilerek, beşli likert ölçeği ile gerçekleştirilmiştir. Tükenmişliğin duygusal boyutunda en yüksek puanlar toplamı 45 'dir. Örgütsel bağlılığın duygusallık boyutunda ise en yüksek puanlar toplamı 40 'dır. Buna göre puanların toplamı ne kadar fazla ise her iki boyutun etkisi o ölçüde yükselmektedir.

Çalı̧̧mada bir adet hipotez kurulmuş ve bu hipoteze göre açıklamalarda bulunulmuştur. Hipotez: Mali müşavirlerin duygusal tükenmişlik algılamaları, duygusal bağlılık düzeylerini etkilemektedir.

Ana kütleyi oluşturan mali müşavir sayısı 5635 iken yeminli mali müşavir sayısı 587dir. (muhasebenews,2018). Toplamda yaklaşık olarak 6200 kişi çalışmanın evrenini oluşturmaktadır. Araştırmadaki örneklem oranı ise yaklaşık olarak yüzde 4 tür. Örneklem ile ilgili araştırma yapanlara yol göstermesi bakımından $\alpha=0.05$ için $+0.03,+0.05$ ve +0.10 örnekleme hataları için birbirinden değişik evren büyüklüklerinden çekilmesi gereken örneklem büyüklükleri hesaplanarak aşağıda formül oluşturulmuştur. (Yazıcıoğlu ve Erdoğan, 2004, s.49-50). $\mathrm{Nt}^{2} \mathrm{pq} / \mathrm{d}^{2}(\mathrm{~N}-1)+\mathrm{t}^{2} \mathrm{pq}$ formülü kullanılarak gerekli örneklem aralıkları oluşturulmuştur. Yazıcoğlu ve Erdoğan(2004)'ın oluşturduğu tabloya göre $\mathrm{p}=0.8 \mathrm{q}=0.2$ aralığında yeterli örneklem aralığı 234-240 aralığındadır. Buna göre 247 anket örneklem için yeterli olmaktadır.

\section{BULGULAR}

Tablo 1. Katılımciların DemografikÖzellikleri

\begin{tabular}{|c|c|c|c|}
\hline DEĞİŞKEN & & FREKANS & YÜZDE \\
\hline \multirow[t]{2}{*}{ CINSIYYET } & ERKEK & 137 & 55,5 \\
\hline & KADIN & 110 & 44,5 \\
\hline \multirow{5}{*}{ YAŞ } & 25 VE ALTI & 34 & 13.8 \\
\hline & $26-35$ & 71 & 28.7 \\
\hline & $36-45$ & 48 & 19.4 \\
\hline & $36-45$ & 47 & 19.0 \\
\hline & $46-55$ & 47 & 19.0 \\
\hline \multirow{5}{*}{ EĞİTİM DURUMU } & LISE & 1 & 0.4 \\
\hline & ÖNLISAANS & 7 & 2,8 \\
\hline & LISANS & 212 & 85,8 \\
\hline & YÜKSEK LİSANS & 26 & 10.5 \\
\hline & DOKTORA & 1 & 0.4 \\
\hline \multirow{3}{*}{ MEDENİ DURUM } & BEKAR & 75 & 30.4 \\
\hline & EVLİ & 160 & 64.8 \\
\hline & BOŞANMIŞ & 12 & 4.9 \\
\hline
\end{tabular}




\section{A. Caner - B. Aydintan 11/3 (2019) 1656-1662}

- Araştırmaya katılan mali müşavirlerin \% 44.5'i kadın, \% 55,5'i erkektir.

- Araştırmaya katılan mali müşavirlerin \%13.8'i 25 yaş ve altında , \%28.7si 26-35 yaş, \% 19,4'ü 36-45 yaş, \% 19'u 46-55 yaş ve\% 19'u 56ve üzeri yaş aralığında yer almaktadır.

- Araştırmaya katılan mali müşavirlerin eğitim düzeylerine bakıldığında \% $0.4^{\prime}$ ü lise ve dengi okullar, \% 2,8'inin önlisans, \%85.8'inin lisans, \% 10.5'inin ise yüksek lisans ve\% $0.4^{\prime}$ 'ünün doktora mezunu olduğu görülmektedir.

- Araştırmaya katılan mali müşavirlerin medeni durumlarına bakıldığında \%30.4'ü bekar, \%64.8'i evli ve \% $4.9^{\prime}$ u boşanmıştır.

Ankette kullanılan ölçekler geçerli olmasına karşın, iç tutarlılık sağlanması açısından ve çalışmanın güvenirliliğini ölçmek için Cronbach alfa güvenilirlik analizi yapılarak, Tablo 2'de gösterilmiştir.. Yapılan analizlerde 247 katılımcıdan elde edilen veriler kullanılmıştır.

Alpha $(\alpha)$ katsayısına bağlı olarak ölçeğin güvenilirliği aşağıdaki gibi yorumlanmaktadır:

$0 \leq \alpha<0.40$ ise ölçek güvenilir değildir,

$0,40 \leq \alpha<0,60$ ise ölçek güvenilirliği düşük,

$0.60 \leq \alpha<0.80$ oldukça güvenilir,

$0.80 \leq \alpha<1.00$ ise ölçek yüksek derecede güvenilir bir ölçektir (Tavşancıl, 2005: 19).

Tablo 2. Ölçek Güvenilirlik Katsayıları

\begin{tabular}{l|cc}
\hline & Madde sayısı & Cronbach alfa değeri \\
\hline Duygusal Tükenmişlik & 9 & 0.834 \\
Duygusal Bağllıı & 8 & 0,918 \\
\hline
\end{tabular}

Yapılan analiz sonucunda; duygusal tükenmişliğin güvenirlik düzeyi 0.834 çıkmıştır. Duygusal bağlılığın güvenirlik düzeyi 0.918 çıkmıştır. Bu durumda güvenirlik düzeyi her iki boyut içinde oldukça yüksektir.

Tükenmişlik ve örgütsel bağlllık düzeyleri arasındaki ilişkinin tespit edilmesine yönelik korelasyon ve regresyon analizleri yapılmıştır. Bu analiz sonuçları aşağıda Tablo3 ve Tablo 4'de gösterilmiştir.

Tablo 3. Değişkenler arası ilişkiler

\begin{tabular}{|l|l|l|}
\hline \multicolumn{3}{|c|}{ Değişkenler Arası İlişkiler } \\
\hline & 1.Duygusal Tükenme & 2.Duygusal Bağlılık \\
\hline 1.Duygusal Tükenme & 1 & $-430^{* *}$ \\
\hline 2.Duygusal Bağlılık & $-430^{* *}$ & 1 \\
\hline
\end{tabular}

Analiz sonucunda duygusal tükenmişlik ile duygusal bağlllık arasında 0.430 'luk negatif yönlü anlamlı $(0,01)$ bir ilişki vardır. Diğer bir tabirle duygusal tükenme ile örgütsel bağlllığın duygusallık boyutu arasında \%43'lük negatif ve anlamlı bir ilişki vardır. İlişkinin varlığı tespit edilmiş olup bu süreçten sonra ise duygusal tükenmişliğin, duygusal bağlllık boyutuna olan etkisi incelenecektir. 


\section{A. Caner - B. Aydintan 11/3 (2019) 1656-1662}

Tablo 4. Duygusal Tükenmişliğin, Duygusal Bağlılığa Olan Etki Düzeyini Belirlemek Üzere Yapılan Regresyon Analizi Sonuçları

\begin{tabular}{|c|c|c|c|c|c|c|}
\hline \multirow[t]{2}{*}{ Model } & \multicolumn{2}{|c|}{ Standart Olmayan Katsayılar } & \multirow{2}{*}{\begin{tabular}{|l} 
Standart \\
Katsayılar \\
Beta
\end{tabular}} & \multirow[t]{2}{*}{ T Değeri } & \multirow[t]{2}{*}{ Anlamlilık } & \multirow[t]{2}{*}{$\mathrm{R}^{2}$} \\
\hline & B & Standart Hata & & & & \\
\hline \multirow{2}{*}{\begin{tabular}{|l|} 
(Sabit) \\
Duygusal Tükenmişlik
\end{tabular}} & 4,802 & 251 & & 19,145 &, 000 & \multirow[t]{2}{*}{207} \\
\hline &,- 610 & 076 &,- 455 & $-8,002$ &, 000 & \\
\hline
\end{tabular}

Bu çalışmada da tek bağımlı tek bağımsız değişken olduğu için $\mathrm{R}^{2}$ değerine bakılmıştır. $B$ katsayısı ise, bağımsız değişkenin etkisini sabit tutarak bağımlı değişkenin etkisini belirlemeyi ifade eder. Pozitif ya da negatif işareti ise bağımsız değişkenle bağımlı değişken arasındaki ilişkinin yönünü belirtir. Tablodaki $\mathrm{R}^{2}$ değerine göre duygusal tükenmişlikteki bir birimlik değişim duygusal bağlılığın \%20.7' sini açıklamaktadır. Anlamlılık derecesi 0.05 anlamlılık derecesinin altında olduğu için anlamlı bir açıklama olmuştur. Yapılan basit regresyon modeline göre duygusal tükenmişliğin duygusal bağlllı̆̆a etkisi negatif yönde 0.610 kadardır. Duygusal tükenmişlik 1 birim artarsa duygusal bağlılık 0,610kadar azalmaktadır.

Buna göre; "Mali müşavirlerin duygusal tükenmişlik algılamaları, duygusal bağlılık düzeylerini etkilemektedir" hipotezi kabul edilmiştir. Genel olarak ise duygusal tükenmişlik, duygusal bağlılığı anlamlı olarak etkilemektedir.

\section{SONUÇ VE TARTIŞMA}

Duygusal tükenmişlik azaltıldığı yada bitirildiği zaman duygusal bağlılığa engel olan olumsuz özellikler de azalmış olacak ve işgörenlerin örgüte bağlllıkları da artmış olacaktır. Bu sebeple duygusal tükenmişliği bitirmek ya da azaltmak için işgörenler, örgütler ve gerekirse devlet bu konuda çalışmalar yapmalı ve bu sendromun etkilerini azaltacak eylemlerde bulunmalıdır. Genel olarak işgörenlerin tükenmişliğini bitirmek veya azaltmak için şunlar yapılabilir:

- İşgörenlere daha fazla söz sahibi olmalarına fırsat verilerek onların görüşlerine değer verilmeli ve çalışanlar arasında karşılıklı güven ortamı tesis edilmelidir.

•Örgütler, işgörenlerle iletişim ve örgütsel iklimi sağlamak adına faaliyetlerde bulunmalı ayrıca çalışanlar arasında güven, işbirliği, yardımlaşma, paylaşma duygularını artırıcı bir ortam hazırlanarak personel güçlendirmeye önem verilmelidir.

•Örgütlerin küresel yönetim ilkelerine uyumlu olması için devlet tarafından yasal düzenlemeler yapılarak işgörenlerin görev tanımları kesin ve belirli olmalıdır.

•İş görenlerin karşı karşıya kaldıkları aşırı iş yükünün olumsuz etkilerini azaltmak amacıyla devlet gerekli önlemleri almalı ve gerekirse mesai saatlerini azaltarak mola ve dinlenme sürelerini artırmalıdır.

-Yöneticiler işgörenler işleri taksim ederken her işgörenin becerisine uygun iş vererek yetki ve sorumlulukları belirlemelidir.

-Yöneticiler işgörenlerle bir araya geleceği toplantılar düzenlemeli ve onların istek ve şikayetlerini dinleyerek çözümler bulmalıdır. Kendisine değer verildiğini hisseden işgörenin duygusal zekası ve örgütsel bağllı̆ı̆ı artacaktır.

- Örgüt içerisinde adalet, güven, sorumluluk gibi kavramlar eyleme dönüştürülmeli ve bütün iş görenlere emeğinin hakkı layıkıyla verilmelidir. Böylece örgüte olan bağlılıkları artacaktır. - Organik örgüt yapıları tesis edilmeli, bilgiye, yeniliğe açık iletişim ve örgüt yapıları oluşturulmalıdır.

-Teknolojik yeniliklere işgörenler kendilerini hazırlamalı ve teknolojik yenilikleri yakından takip etmelidir.

•İsgörenler spora, beslenmeye önem vermeli ve hayatlarını devamlı bir program dahilinde sürdürerek zaman yönetimini öğrenmelidirler.

•İşgörenler iletişime önem vermeli ve problemleri çözmeye çalışmalı ve en kısa sürede gerekli mercilere iletmelidirler. 


\section{A. Caner - B. Aydintan 11/3 (2019) 1656-1662}

\section{KAYNAKÇA}

Baysal, A.C. ve Paksoy, M. (1999). “Mesleğe ve örgüte bağlllı̆̆ın çok yönlü incelenmesinde Meyer-Allen modeli". İstanbul Üniversitesi İşletme Fakültesi Dergisi, 2(1), 7-15

Budak, G. Sürgevil, O. (2005). “Tükenmişlik ve tükenmişliği etkileyen örgütsel faktörlerin analizine ilişkin akademik personel üzerinde bir uygulama". Dokuz Eylül Üniversitesi İktisadi ve İdari Bilimler Fakültesi Dergisi, 20 (2), 95-108.

Civanoğlu S.P. (2015). Duygusal Zeka ile Tükenmişlik ve Örgütsel Bağlılık Düzeyleri Arasındaki İlişkinin İncelenmesi Üzerine Bir Araştırma. Yüksek Lisans Tezi, Beykent Üniversitesi Sosyal Bilimler Enstitüsü, Ankara.

Çalgan, Z. Yeğenoğlu S. (2009). Eczacılarda Mesleki Bir Sağllk Sorunu: Tükenmişlik, Hacettepe Üniversitesi Eczacilı Fakültesi Dergisi, 29(1), 61-74.

Emhan, A. ve Gök, R.(2011). “Bankacılık Sektöründe Personel Memnuniyeti ve Örgütsel Bağlllık Arasındaki İlişkilerin Araştırılması". Muhasebe ve Finansman

Güleryüz, G., Güney, S., Aydın, E.M. ve As, Ö. (2008). “The Mediating Effectof Job Satisfaction Between Emotional İntelligence and Organisational Commitment of Nurses: A Questionnaire Survey". International Journal of Nursing Studies, 45, 1625-1635.

İnternet:https://www.google.com/search?rct=j\&q=Muhasebenews.com.tr\%20Ekim\%29\%2C2018(Erişimtarihi: 14 Ocak 2019)

İnternet:http://www.tdk.gov.tr/index.php?option=com_bts\&view=bts\&kategori1=veritbn\&kelimesec=320524 ( Erişim tarihi: 25 Kasım 2018)

Maslach, C., Jackson S. E. (1981. “The Measurement of Experienced Burnout”.Journal of Occupational Behavior, 2, $99-113$.

Özgüner, M. (2011). “Örgüt Kültürü ve Tükenmişlik İlişkisi Üzerine Bir Araştırma: Bozok Üniversitesi Örneği". Yayınlanmamış Yüksek Lisans Tezi, Bozok Üniversitesi, Sosyal Bilimler Enstitüsü, Yozgat.

Tavşancıl, E. (2005). Tutumların Ölçülmesi ve SPSS İle Veri Analizi. Ankara: Nobel, 19.

Tosun, K. (1987).İşletme Yönetim(4.Baskı), İstanbul: C.I.Yön Ajans Matbaası,224.Dergisi, Temmuz, 157-174.

Ülgen H.(1997).İşletmelerde Organizasyon İlkeleri ve Uygulaması (3.Baskı). İstanbul: İşletme Fakültesi Yayını, 44.

Üresin T.(2009). Tükenmişlik Ve Örgütsel Bağlllık Arasındaki İlişki, Yüksek Lisans Tezi, Marmara Üniversitesi Sosyal Bilimler Enstitüsü,İstanbul.

Yazıcıoğlu, Y. ve Erdoğan, S. (2004). Spss Uygulamalı Bilimsel Araştırma Yöntemleri. Ankara: Detay Yayıncilık,78. 